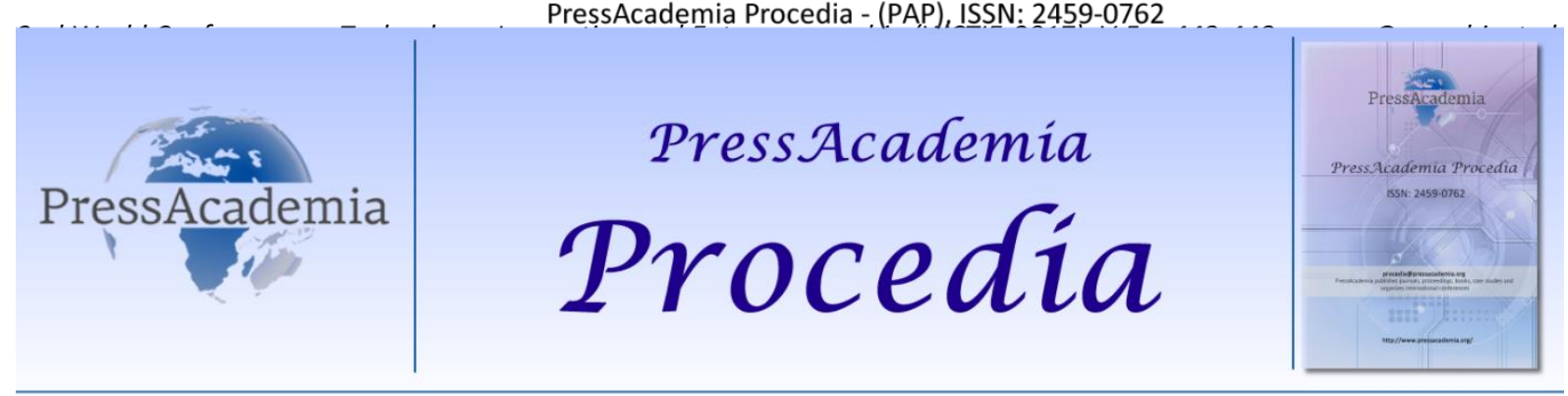

2nd World Conference on Technology, Innovation and Entrepreneurship

May 12-14, 2017, Istanbul, Turkey. Edited by Sefer Şener

\title{
STUDY OF THE INFLUENCE OF WASTE OF PLASTIC ON THE MECHANICAL BEHAVIOR OF MODIFIED BITUMINOUS CONCRETE
}

DOI: 10.17261/Pressacademia.2017.622

PAP-WCTIE-V.5-2017(60)-p.443-448

\author{
N. Guessabi ${ }^{1}$, K. Soudani ${ }^{2}$, S. Saoula ${ }^{3}$, S. Haddadi ${ }^{4}$ \\ 1.LEEGO, FGC, USTHB, Algiers, Algeria, nguessabi@yahoo.fr \\ 2.LEEGO, FGC, USTHB, Algiers, Algeria, soudani.khedoudja@yahoo.com \\ 3.LEEGO, USTHB, UMBB, Boumerdes, Algiers, Algeria,, ssaoula1@yahoo.fr \\ 4.LEEGO, FGC, USTHB, Algiers, Algeria,, shaddadi@usthb.dz
}

\begin{abstract}
The objective of this work is the study of the influence of the addition of plastic waste on the behavior of modified asphalt mixtures. Two mechanical tests were conducted on the modified bituminous concrete by the waste of plastic. Different contents of waste were used. The modification was performed by the dry method. The mechanical tests were : Marshall test and the indirect tensile strength test. This study showed that adding waste of plastic to asphalt mix improves their mechanical performances, such as increased stability, compactness, Marshall quotient and indirect tensile strength ITS and decreased Marshall flow and the deformation in the indirect tensile strength test. In addition to the interest of the use of plastic waste in road construction, there is a positive influence on the environment and human life by reducing storage areas of these plastics pollutants
\end{abstract}

Keywords: Plastic waste, marshall test, indirect tensile strength test.

\section{INTRODUCTION}

The Road pavement structures are a much newer design. The use of bituminous materials has emerged with the new problems posed by the movement of motor vehicles from the late nineteenth century. Traditional mixes, usually respond satisfactorily to traffic loads. However, changes in the traffic in terms of volume and aggressiveness, and application techniques, both increasingly demanding with regard to the quality of asphalt concrete, has shown some limitations in their jobs and pushed researchers to find solutions for improving the performance of asphalt concrete by adding various compounds. Of these, polymers dominate. For economic reasons related to oil shocks of the 1970s, the road techniques were oriented for over two decades to build roads with thinner layers. These structures must nevertheless ensure mechanical properties at least equivalent to those of traditional pavements. The appearance of special asphalt concrete, asphalt concrete draining, asphalt concrete high modulus, asphalt concrete resistant to hydrocarbons, etc., requires additives of performance in terms of cohesion, adhesion, resistance to chemicals whose oxidation and mechanical stress that is not available in all circumstances in asphalt mixtures with pure bitumen.

The rutting met remains the most damage on the pavement. The creep of asphalt mixture is responsible (Haddadi, 2007), (Proteau and Paquin, 2001). For reduce this phenomena, various techniques have been undertaken. Among them, modification of asphalt with the polymer became a promising technique (Frantzis, 2004) (Khosla and Zahran, 1989).

Modification of asphalt mixtures with compatible polymers or waste can be beneficial. It can be performed:

- $\quad$ by modifying of bitumen by addition of polymers, tires, chemical and other, it is the wet process.

- $\quad$ by modifying the asphalt mixture in the plant by adding polymer type additive, crumb from tires (Haddadi, 2007), plastic food packaging waste (Guessabi, 2011) and others, it is the dry process. 
To satisfy the sustainability criteria of road surfaces, it should develop an effective bituminous mixture, which is modified bituminous concrete.

The objective of this work is to study the resistance of wearing rutting under the effect of traffic, by modifying the asphalt concrete with a polymer, which is the plastic food packaging waste.

\section{MATERIALS AND METHODS}

\subsection{The Bitumen}

The bitumen (35/50) comes from refineries of NAFTAL (Algeria). Conventional tests are those of the penetration at $25^{\circ} \mathrm{C}$ (NF EN 1426), of the ball and ring temperature (NF EN 1427) and ductility at $25^{\circ} \mathrm{C}$. The results obtained are:

TBA: $51^{\circ}$ C; Penetration: $40(1 / 10 \mathrm{~mm})$; Ductility :> $100(\mathrm{~cm})$. These characteristics are in accordance with the specifications recommended for the class (35/50).

\subsection{The Aggregates}

Three crushed granular classes (0/3 sand, $3 / 8$ and $8 / 15$ gravel from the quarry of El Hachemia (wilaya of Boumerdes). Chemical analysis was performed on these aggregates where we found that they are natural limestone with high $\mathrm{CaCO} 3$ content of the three granular fractions. After various tests (LA, MDE, cleanliness, etc.) (NF EN 1097-1) (NF EN 1097-2). The selected materials present good qualities of intrinsic characteristics. The figure 1 shows the particle size analysis of the granular fractions.

Figure 1: Particle Size Analysis of Aggregates

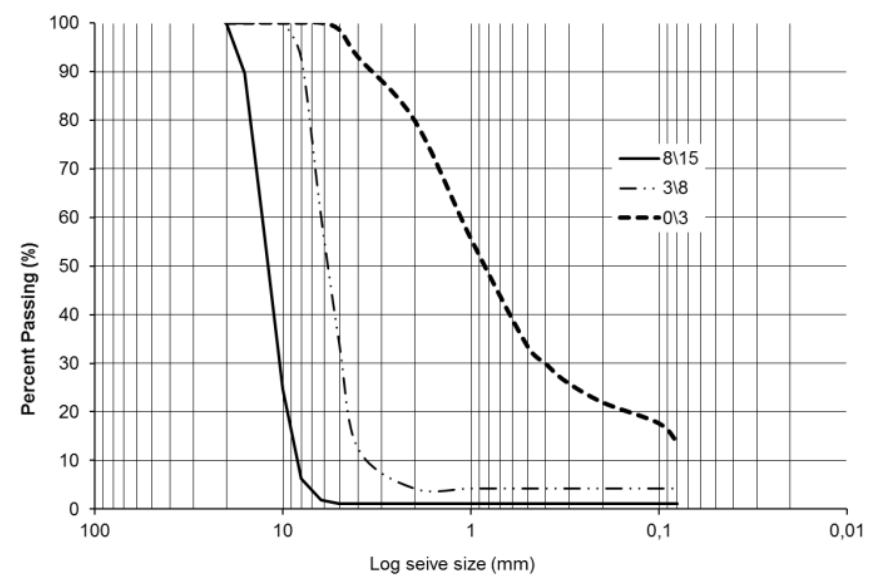

\subsection{Identification of the Modifier Used}

The additive used in this study is a waste plastic of food; they are packing bags. The preparation of plastic waste is made in the laboratory of roads. The procedure is to cut the plastic bags in varying fiber length of 2 to $5 \mathrm{~mm}$ (Guessabi, 2011). Figure 2 shows the plastic waste used in this study.

Figure 2: The Plastic Waste

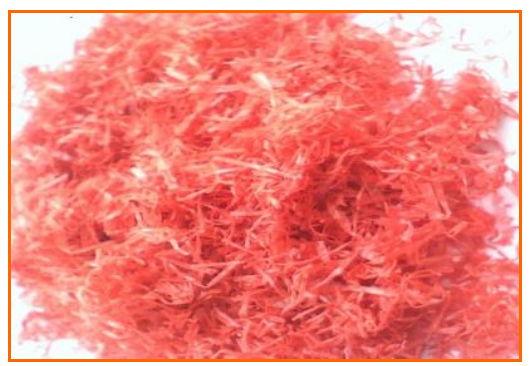




\section{FORMULATION OF ASPHALT CONCRETE}

The particle size distribution curve shown in Figure 3 that is inserted in the specification curve is obtained for the following proportions (Guessabi, 2011):

$-40 \%$ of sand $0 / 3$

- $30 \%$ of the fraction $3 / 8$

- $30 \%$ of the fraction $8 / 15$

Figure 3: Mixture Curve

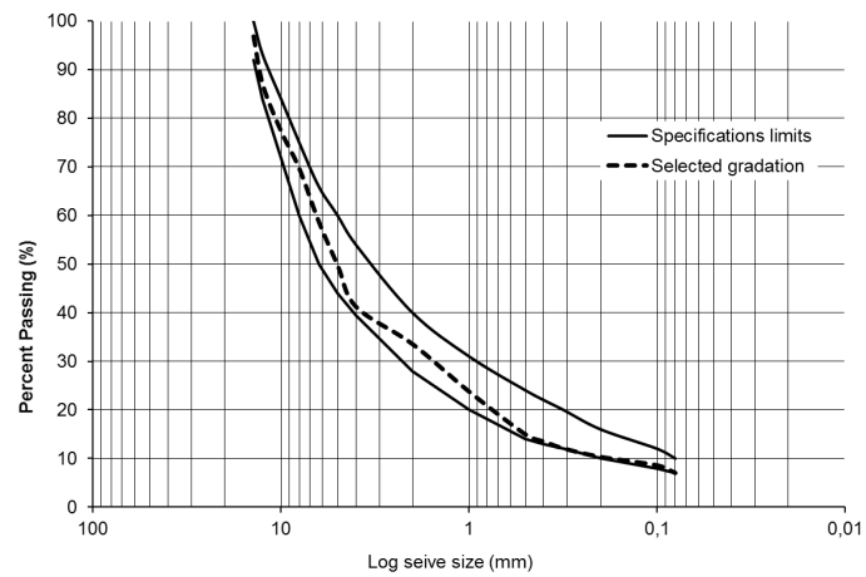

In this formulation study, for the formula used (40\% of $0 / 3,3 / 830 \% ; 30 \% 8 / 15)$, the optimum content is obtained for a bitumen content of $5.77 \%$ giving the best Marshall test characteristics. This content will be considered in this study as that of the bituminous concrete of control or reference without modification.

\section{THE MODIFIED BITUMINOUS CONCRETE BY DRY METHOD}

The bituminous mix is manufactured according to the previously defined proportions of the different fractions of aggregates and bitumen (NF P98-250-1, 1992), the amount of the additive is chosen as a weight percentage of the aggregate. The choosen percentages are $0.1 ; 0.2 ; 0.3 ; 0.5 ; 0.6 ; 0.7 ; 0.8$ and $1 \%$ of plastic waste. The additive is incorporated with the aggregate skeleton during mixing operation, the bitumen is introduced thereafter. Once concrete bituminous Marshall type specimens are made.

To assess the impact of plastic waste on the mechanical performance of the mix, we performed the following Marshall Test (NF EN 12697-34) and indirect tensile strength test (NF EN 12697-23).

\subsection{Results of the Marshall Test}

The results of Marshall Test (stability, flow and quotient) are shown in Figures 4 to 6.

\section{Figure 4. Marshall Stability versus Plastic Waste Content}

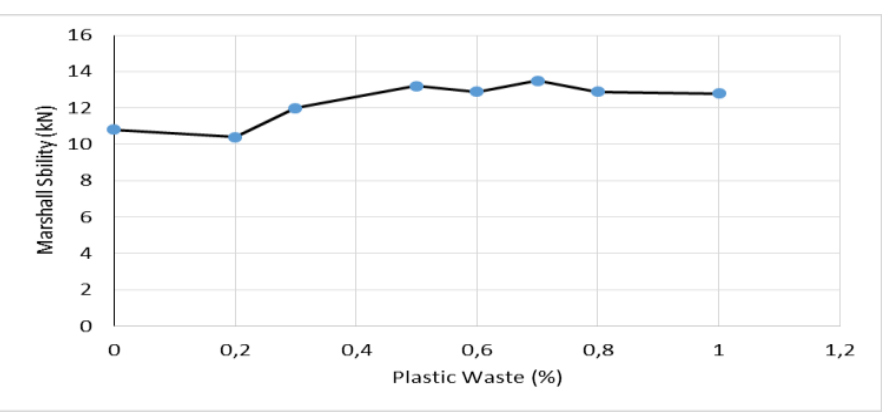


Figure 5: Marshall Flow versus Plastic Waste Content

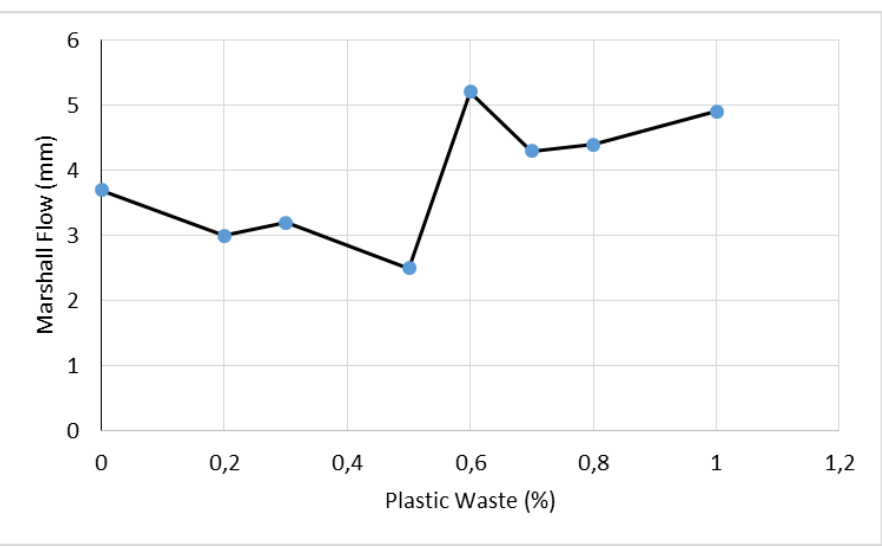

Figure 6: Marshall Quotient versus Plastic Waste Content

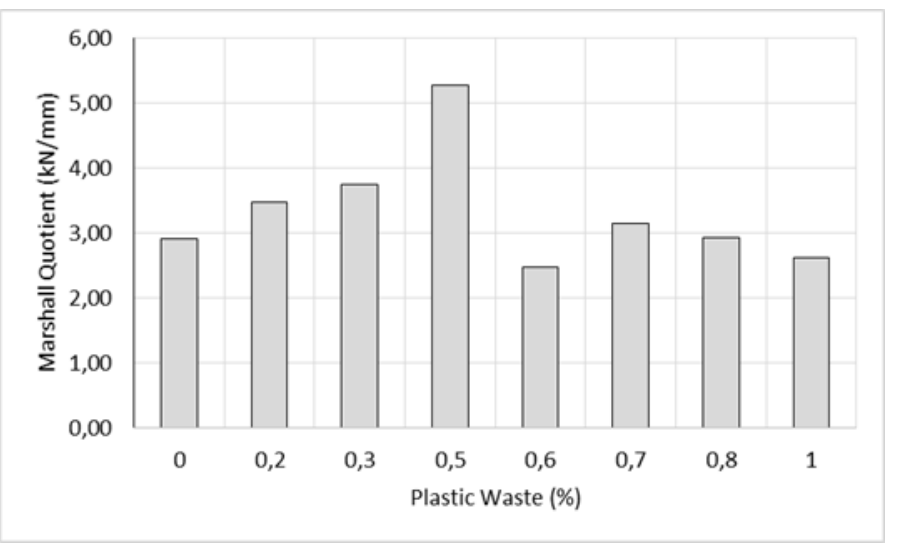

The curves of Figures 4 to 6 show that the incorporation of plastic waste improves the Marshall quotient in the bituminous mixture and improves so the resistance for permanent deformation (Haddadi al, 2008). The best results are obtained for the percentage of plastic waste $0.5 \%$ (stability, flow and quotient).

\subsection{Test Results of the Indirect Tensile Strength}

The indirect tensile strength is the maximum tensile stress calculated from the maximum load at the rupture. We chose the contents of $0 \%, 0.3 \%, 0.5 \%$ and $0.7 \%$. The bituminous concrete to $0 \%$ is the reference mixture.

The results of the indirect tensile strength test for both temperatures $20^{\circ} \mathrm{C}$ and $40^{\circ} \mathrm{C}$ are shown in Figures 7 to 9 . 
Figure 7: The Maximum Breaking Load to the Indirect Traction Test

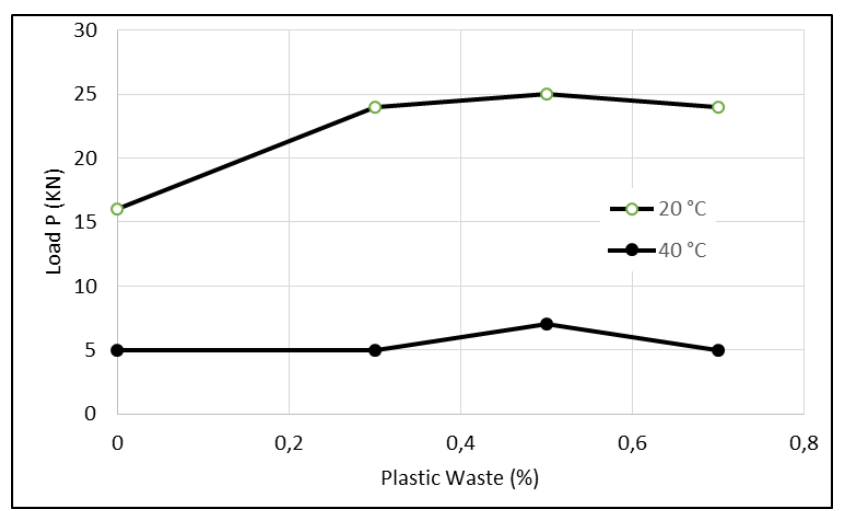

Figure 8: The Deformations According to the Plastic Waste Content to the Indirect Tensile Test

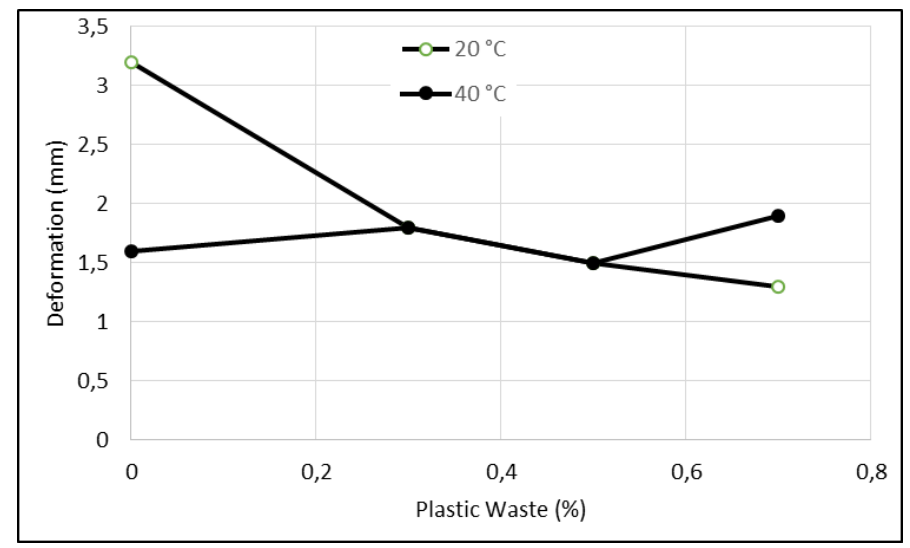

Figure 9: ITS According to the Plastic Waste Content

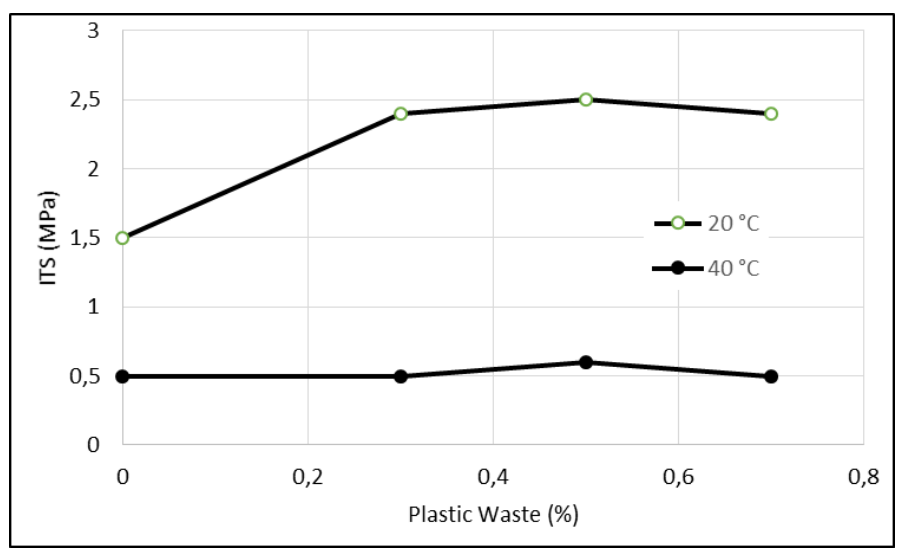

The curves of the test of indirect traction show that the incorporation of plastic waste substantially improves the resistance at $20^{\circ} \mathrm{C}$ but at $40^{\circ} \mathrm{C}$ the improvement is less. 


\section{CONCLUSION}

The addition of plastic waste on asphalt highlighted the following experimental results (Guessabi, 2011):

\subsection{Marshall Test}

- The modification of the bituminous mix by the plastic waste improves its mechanical characteristics, increasing the Marshall stability and reduction of flow and consequently improves the Marshall quotient.

- The modified bituminous concrete at $0.5 \%$ give the best mechanical performances (stability and flow) for the Marshall test compared to the other mixtures.

\subsection{Indirect Tensile Test}

- The best resistance to indirect tensile is obtained at $20{ }^{\circ} \mathrm{C}$ and $40{ }^{\circ} \mathrm{C}$ by the asphalt concrete at $0.5 \%$ content of plastic waste

- The mixture of $0.5 \%$ of plastic waste gives greater rigidity than that of the bituminous concrete control.

\section{REFERENCES}

Haddadi S. (2007). Influence de la poudrette de caoutchouc sur le comportement au fluage des Enrobés bitumineux .Thèse de Doctorat d'état, FGC/USTHB FGC/USTHB 2007.

Proteau M., and Paquin Y. (2001). Contribution de différents bitumes purs et bitumes modifiés par ajout de polymères à la résistance à l'orniérage. Revue Générale Routes et Aérodromes, 793, 34-39.

Frantzis, P. (2004). "Crumb Rubber-Bitumen Interactions: Diffusion of Bitumen into Rubber." J. Mater. Civ. Eng., 10.1061/(ASCE)08991561(2004)16:4(387), 387-390.

Guessabi N. (2011). Guessabi.N, Etude de l'influence du déchet plastique sur le comportement à la traction indirecte des enrobés bitumineux modifies, Mémoire de magister, USTHB/FGC, Algerie.

Khosla N.P. and Zahran S.Z. (1989). A mechanistic evaluation of mixes containing conventional and polymer modified (styrelf) asphalts. Proc Assoc Asphalt Paving Technol ; 58:274-302.

Haddadi S., Ghorbel E. and Laradi N. (2008). Effects of the manufacturing process on the performances of the bituminous binders modified with EVA. Construction and Building Materials, Volume 22, 2008, pp 1212-1219. 